\title{
Dietary sucrose and cd36 receptor in non-alcoholic fatty liver disease (NAFLD)
}

\begin{abstract}
Ingestion of dietary sucrose or fructose or in sweetened beverages causes lipogenesis in the enterocyte to form fatty acids (FA), which are transported by chylomicrons to the liver and adipose tissue; however, the lipolysis of adipocyte during insulin resistance releases FA that are carried to hepatic tissue and are introduced in hepatocyte through CD36 receptor; these events are closely related to the formation of hepatic steatosis and development of Non-Alcoholic Fatty Liver Disease (NAFLD).
\end{abstract}

Keywords: fatty liver, cd36, sucrose, lipogenesis, steato-hepatitis
Volume 3 Issue 5 - 2017

\author{
Maldonado IA, ${ }^{2}$ Sagastume IE, ${ }^{2}$ López Gil \\ $\mathrm{OM},{ }^{2}$ Alexander Aguilera AI, \\ 'Facultad de Bioanálisis, Universidad Veracruzana, México \\ ${ }^{2}$ División de Ciencias de la Salud, Universidad Cristóbal Colón, \\ México
}

Correspondence: Alexander Aguilera A, Facultad de Bioanálisis, Universidad Veracruzana. Carmen Serdán s/n, Col Flores Magón, Veracruz, Ver 91700 , México, Tel 01 -(229)-932-1707,Email aalexander_2000@yahoo.com, aalexander@uv.mx
Abbreviations: NAFLD, non-alcoholic fatty liver disease; NASH, non alcoholic steatohepatitis; VLDL, very low density lipoprotein; FA, fatty acids; GLUT, glucose transporter; F-1-P, fructose-1-posphate; G-6-P,glucose-6-posphate; TG, triglycerides

\section{Introduction}

In the development of Non-Alcoholic Fatty Liver Disease (NAFLD), important biomolecules such as sucrose and dietary fructose give rise de novo lipogenesis causing hepatic steatosis. On the other hand, fatty acids which are released from adipose tissue during the lipolysis (in insulin resistance) are transported to the liver and introduced in the hepatocyte by the CD36 receptor (transmembrane glycoprotein), favoring the pathogenesis of fatty liver (Figure 1).

\section{Intake of sucrose and hepatic steatosis}

Non-alcoholic fatty liver disease (NAFLD) defines a group of diseases ranging from simple steatosis to inflammatory steatohepatitis (NASH) with increasing levels of fibrosis and, finally, cirrhosis. ${ }^{1,2}$ The prevalence of NAFLD has risen considerably globally and represents the most important cause of liver disease in the Western countries. ${ }^{3}$

In many cases, NAFLD is associated with one or more features of the metabolic syndrome: insulin resistance, glucose intolerance or diabetes, central obesity, dyslipidemia and hypertension. ${ }^{4-6}$ One of the most important causes of steatosis is the nutritional factors. Fructose consumption and/or sugar-sweetened beverages represent a potential risk for metabolic syndrome and diabetes..$^{7-10}$ The utilization of fructose in liver metabolism is not restricted by the rate-limiting step of phosphofructokinase, avoiding the regulating action of insulin. ${ }^{11}$ Fructose intake is 2-3 fold higher in patients with NASH and recently daily fructose ingestion has been associated with increased hepatic fibrosis. ${ }^{7,12}$ Numerous epidemiologic studies show a link between sugars sugar consumption, particularly in the form of sugar-sweetened beverages, and various adverse metabolic consequences. ${ }^{13-19}$ A small amount of the fructose taken up by the liver may be converted in the process of lipogenesis into fatty acids (FA). These FA are converted to triglycerides in the hepatocytes and are released into the systemic circulation complexed with the VLDL. However, it has been postulated the participation of FA in the development of fructose-induced hepatic steatosis, particularly when large doses of this sugar is administered. ${ }^{20}$

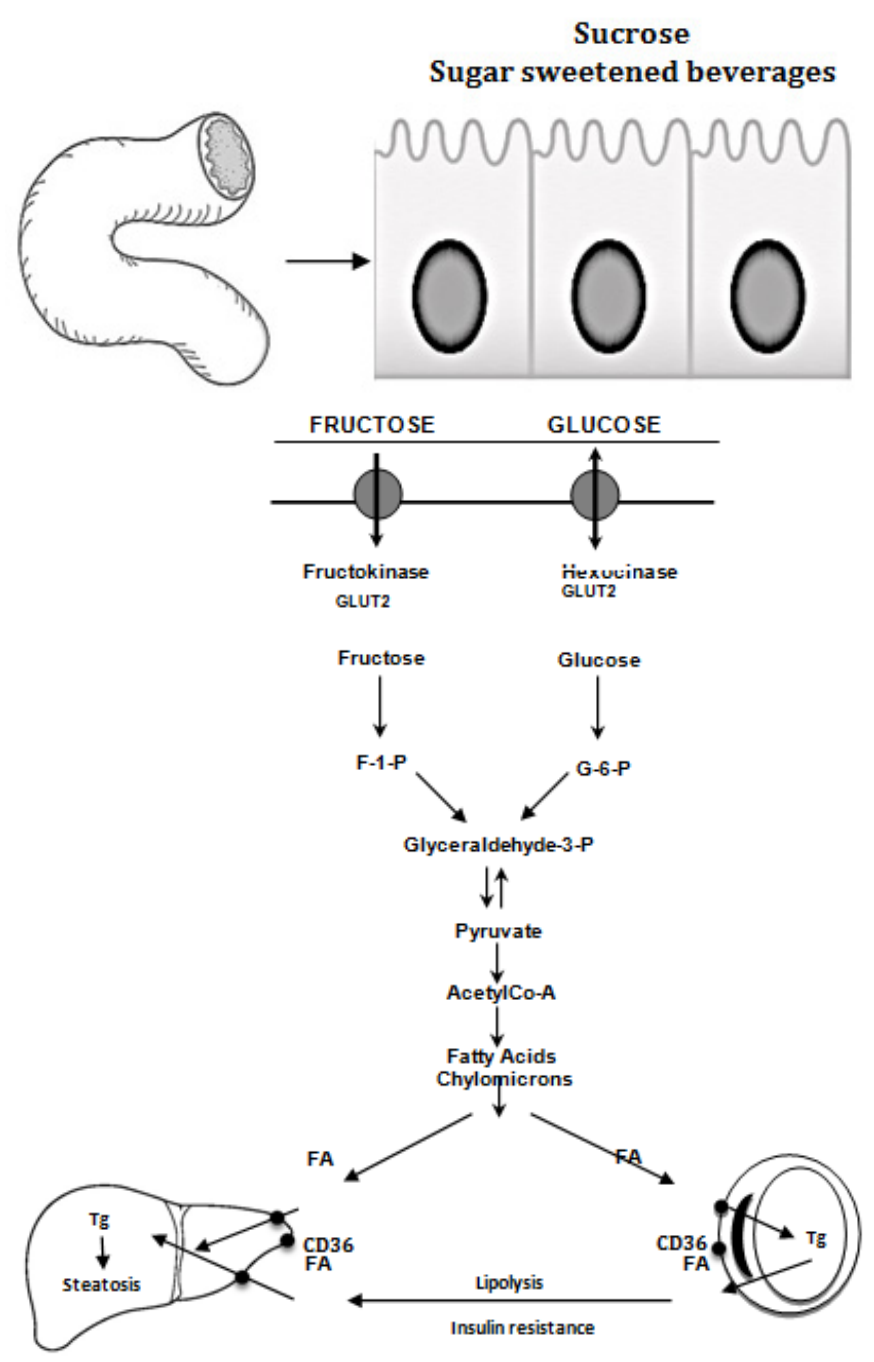

Figure I Interrelation between intestinal lipogenesis from sucrose for the transport of triglycerides and fatty acids to adipose and hepatic tissues, and the participation of the CD36 receptor in the development of steatosis and fatty liver. 


\section{CD36 receptor and fatty liver}

CD36 is a transmembrane glycoprotein present on platelets, mononuclear phagocytes, adipocytes, hepatocytes, myocytes and others. ${ }^{21-22}$ Is also known to have functions as a facilitator of long chain fatty acid transport. ${ }^{23}$

In animal models, ablation of CD36-mediated lipid uptake into liver or muscle prevented lipotoxicity ${ }^{24}$ and other researches, in which CD36 was specifically induced in the liver by pharmacologic means or cDNA transduction; it may lead to steatosis, associated with metabolic disorders. ${ }^{25}$ Overexpression of CD36 increases FA uptake and triglyceride storage in human hepatic cells and the liver of C57BL6 mice. ${ }^{26,27}$ In patients with NAFLD, CD36 up-regulation is significantly associated with hepatic fat accumulation. ${ }^{28}$

\section{Conclusion}

In conclusion, all these findings related with sucrose intake and hepatic lipogenesis, suggest that hepatic CD36 expression is closely related to hepatic steatosis in development of Non-alcoholic fatty liver (NAFLD) in humans and animal models.

\section{Acknowledgements}

None.

\section{Conflicts of interest}

Author declares that there is no conflict of interest.

\section{References}

1. Ludwig J, Viggiano TR, McGill DB, et al. Nonalcoholic steatohepatitis: Mayo Clinic experiences with a hitherto unnamed disease. Mayo Clin Proc. 1980;55(7):434-438.

2. De Alwis NM, Day CP. Non-alcoholic fatty liver disease: the mist gradually clears. J Hepatol. 2008;48(Suppl 1):S104-S112.

3. Petta S, Muratore C, Craxì A. Non-alcoholic fatty liver disease pathogenesis: the present and the future. Dig Liver Dis. 2009;41(9):615-625.

4. Day CP. From fat to inflammation. Gastroenterology. 2006;130(1):207-210.

5. Adams LA, Feldstein A, Lindor KD, et al. Nonalcoholic fatty liver disease among patients with hypothalamic and pituitary dysfunction. Hepatology. 2004;39(4):909-914.

6. Loria P, Carulli L, Bertolotti M, et al. Endocrine and liver interaction: the role of endocrine pathways in NASH. Nat Rev Gastroenterol Hepatol. 2009;6(4):236-247.

7. Stefan N, Kantartzis K, Häring HU. Causes and metabolic consequences of Fatty liver. Endocr Rev. 2008;29(7):939-960.

8. Havel PJ. Dietary fructose: implications for dysregulation of energy homeostasis and lipid/carbohydrate metabolism. Nutr Rev. 2005;63(5):133-157.

9. Johnson RJ, Segal MS, Sautin Y, et al. Potential role of sugar (fructose) in the epidemic of hypertension, obesity and the metabolic syndrome, diabetes, kidney disease, and cardiovascular disease. Am J Clin Nutr 2007;86(4):899-906.
10. Palmer JR, Boggs DA, Krishnan S, et al. Sugar-sweetened beverages and incidence of type 2 diabetes mellitus in African American women. Arch Intern Med. 2008;168(14):1487-1492.

11. Swarbrick MM, Stanhope KL, Elliott SS, et al. Consumption of fructosesweetened beverages for 10weeks increases postprandial triacylglycerol and apolipoprotein-B concentrations in overweight and obese women. $\mathrm{Br}$ J Nutr. 2008;100(5):947-952.

12. Preiss D, Sattar N. Non-alcoholic fatty liver disease: an overview of prevalence, diagnosis, pathogenesis and treatment considerations. Clin Sci (Lond). 2008;115(5):141-150

13. Olsen NJ, Heitmann BL. Intake of calorically sweetened beverages and obesity. Obes Rev. 2009;10(1):68-75.

14. Malik VS, Popkin BM, Bray GA, et al. Sugar-sweetened beverages and risk of metabolic syndrome and type 2 diabetes: a meta-analysis. Diabetes Care. 2010;33(11):2477-2483.

15. Bray GA. Fructose and risk of cardiometabolic disease. Curr Atheroscler Rep. 2012;14(6):570-578.

16. Lustig RH. Fructose: it's alcohol without the buzz. Adv Nutr 2013;4:226-235.

17. Malik VS, Popkin BM, Bray GA, et al. Sugar-sweetened beverages, obesity, type 2 diabetes mellitus, and cardiovascular disease risk. Circulation. 2010;121(11):1356-1364.

18. Ruxton $\mathrm{CH}$, Gardner EJ, McNulty HM. Is sugar consumption detrimental to health? A review. Crit Rev Food Sci Nutr. 2010;50(1):1-19.

19. Woodward-Lopez G, Kao J, Ritchie L. To what extent have sweetened beverages contributed to the obesity epidemic? Public Health Nutr. 2011;14(3):499-509.

20. Tappy L, Le KA. Metabolic effects of fructose and the worldwide increase in obesity. Physiol Rev. 2010;90(1):23-46.

21. Silverstein RL, Febbraio M. CD36, a scavenger receptor involved in immunity, metabolism, angiogenesis, and behavior. Sci Signal. 2009;2(72):re3.

22. Zhang X, Fitzsimmons RL, Cleland LG, et al. CD36/fatty acid translocase in rats: distribution, isolation from hepatocytes, and comparison with the scavenger receptor SR-B1. Lab Invest. 2008;83(3):317-332.

23. Coburn CT, Knapp FF Jr, Febbraio M, et al. Defective uptake and utilization of long chain fatty acids in muscle and adipose tissues of CD36 knockout mice. J Biol Chem. 2009;275(42):32523-32529.

24. Yang J, Sambandam N, Han X, et al. CD36 deficiency rescues lipotoxic cardiomyopathy. Circ Res. 2007;100(8):1208-1217.

25. Zhou J, Febbraio M, Wada T, et al. Hepatic fatty acid transporter Cd36 is a common target of LXR, PXR, and PPARgamma in promoting steatosis. Gastroenterology. 2008;134(2):556-567.

26. Malik IA, Moriconi F, Sheikh N, et al. Single-dose gamma-irradiation induces up-regulation of chemokine gene expression and recruitment of granulocytes into the portal area but not into other regions of rat hepatic tissue. Am J Pathol.2010;176(4):1801-1815.

27. Christiansen H, Batusic D, Saile B, et al. Identification of genes responsive to gamma radiation in rat hepatocytes and rat liver by cDNA array gene expression analysis. Radiat Res. 2006;165(3):318-325.

28. Bligh EG, Dyer WJ. A rapid method of total lipid extraction and purification. Can J Biochem Physiol. 1959;37(8):911-917. 